\title{
PREDIÇÃO DA DEMANDA QUÍMICA DE OXIGÊNIO EM CHORUME MADURO CONTENDO REAGENTE DE FENTON, POR MEIO DE MODELO MATEMÁTICO EMPÍRICO GERADO COM PLANEJAMENTO FATORIAL COMPLETO
}

\author{
André Luís de Castro Peixoto, Renata Alves de Brito, Rodrigo Fernando dos Santos Salazar, Oswaldo Luiz Cobra \\ Guimarães e Hélcio José Izário Filho* \\ Departamento de Engenharia Química, Escola de Engenharia de Lorena, Universidade de São Paulo, Estrada Municipal do \\ Campinho, s/n, 12602-810 Lorena - SP, Brasil
}

Recebido em 12/7/07; aceito em 16/4/08; publicado na web em 19/9/08

\begin{abstract}
PREDICTION OF CHEMICAL OXYGEN DEMAND IN MATURE LANDFILL LEACHATE DOPED WITH FENTON'S REAGENT, USING EMPIRICAL MATHEMATICAL MODEL OBTAINED BY FULL FACTORIAL DESIGN. COD is an important parameter to estimate the concentration of organic contaminants. The closed system technique with the use of $\mathrm{K}_{2} \mathrm{Cr}_{2} \mathrm{O}_{7}$ is the most important one, however, it has the inconvenience to suffer positive chemical interferences from inorganic compounds such as $\mathrm{Fe}^{2+}$ and $\mathrm{H}_{2} \mathrm{O}_{2}$ (not enough reported in the literature). This paper considers a statistical-experimental set capable to validate a empirical mathematical model generated from a 23 experimental design, in the presence of $\mathrm{Fe}^{2+}$ and $\mathrm{H}_{2} \mathrm{O}_{2}$. The $\mathrm{t}$ test shows that mathematical model has $99,99999 \%$ confidence degree and the experimental validation test indicates absolute mean error of $4,70 \%$.
\end{abstract}

Keywords: chemical oxygen demand; inorganic interferences; design of experiments.

\section{INTRODUÇÃO}

A demanda química de oxigênio é um parâmetro importante para estimativa da concentração de contaminantes orgânicos em fontes de água. Uma vez que a degradação de compostos orgânicos necessita de oxigênio, as concentrações destas substâncias podem ser estimadas pela quantidade de oxigênio requerida. ${ }^{1} \mathrm{Na}$ determinação da DQO, o método em sistema fechado com uso do agente oxidante dicromato ${ }^{2}$ é o mais importante devido à sua capacidade oxidante superior, à sua aplicabilidade em uma grande variedade de amostras e à facilidade de operação. Espécies inorgânicas como $\mathrm{O}_{2}^{2-}, \mathrm{Fe}^{2+}$, halogênios e $\mathrm{SO}_{2}$, que possuem caráter redutor, são capazes de reduzir o dicromato de potássio, interferindo positivamente no resultado da análise. A interferência de cloreto e nitrito pode ser prevenida por adição de sulfato mercúrico e ácido sulfâmico, respectivamente. Contudo, um método para corrigir a interferência de espécies inorgânicas como o $\mathrm{Fe}^{2+}$ e $\mathrm{H}_{2} \mathrm{O}_{2}$ não é mencionado no Standard Methods, ${ }^{2}$ e é, também, insuficientemente relatado na literatura. A combinação dessas duas espécies químicas resulta em um dos mais importantes Processos Oxidativos Avançados (POAs), o chamado reagente de Fenton, que tem sido largamente estudado no tratamento de efluentes industriais. ${ }^{3}$

Planejamento de experimentos é definido como um conjunto de técnicas estatísticas aplicadas ao planejamento, condução, análise e interpretação de testes controlados, buscando encontrar (definir) os fatores que influenciam os valores de um parâmetro ou um grupo de parâmetros. ${ }^{4}$ Seu princípio básico permite variar de uma só vez, todos os níveis de todas as variáveis, discretas ou contínuas (chamadas de fatores), a cada experiência, de maneira programada e racional. $\mathrm{O}$ experimentador pode reduzir o tempo e o custo de trabalho, diminuindo o número de pontos de experiência por fator, sem ser obrigado a limitar o número de fatores, como ocorre no método clássico de experimentação. ${ }^{5}$ Dentre as metodologias envolvidas na técnica de planejamento de experimentos encontra-se o modelamento matemático do conjunto de experimentos executados pelo experimentador.

*e-mail: helcio@dequi.eel.usp.br
Segundo Galdámez, ${ }^{6}$ o modelo estatístico do experimento fatorial $2^{3}$ para o conjunto de fatores $\mathrm{x}_{1}, \mathrm{x}_{2}$ e $\mathrm{x}_{3}$ é dado pela Equação 1

$y_{i j k}=\mu+\tau_{i}+\beta_{j}+\gamma_{k}+\left(\tau \beta_{i j}\right)+\left(\tau \gamma_{i k}\right)+\left(\beta \gamma_{j k}\right)+\left(\tau \beta \gamma_{i j k}\right)+\xi_{i j k}$

sendo que $\mu$ é a média dos resultados; $\tau_{i}$ é o efeito principal do fator $\mathrm{x} 1 ; \beta_{j}$ é o efeito principal do fator $\mathrm{x} 2 ; \gamma_{k}$ é o efeito principal do fator $\mathrm{x} 3$; $\left(\tau \beta_{i j}\right)$ é o efeito de interação entre os fatores x 1 e x $2 ;\left(\tau \gamma_{i k}\right)$ é o efeito de interação entre os fatores x1 e x3; $\left(\beta \gamma_{j k}\right)$ é o efeito de interação entre os fatores x 2 e x $3 ;\left(\tau \beta \gamma_{i j k}\right)$ é o efeito de interação entre os fatores x1, $\mathrm{x} 2$ e $\mathrm{x} 3$; e $\xi_{i j k}$ é o erro experimental.

Talinli e Anderson ${ }^{7}$ estudaram o grau de interferência do peróxido de hidrogênio no teste padrão de DQO para amostras sintéticas (solução de glicose em diferentes concentrações) e reais (efluentes de indústrias têxteis, de branqueamento, de polpa e papel e de plásticos). Em um primeiro momento, os autores tentaram eliminar $\mathrm{o}_{2} \mathrm{O}_{2}$ por aeração após 5, 10 e $30 \mathrm{~min}$. Em nenhum momento o processo de aeração reduziu o interferente. Em um segundo momento, buscou-se degradar o $\mathrm{H}_{2} \mathrm{O}_{2}$ com os reagentes permanganato de potássio, tiossulfato de sódio, azida de sódio, sulfeto de potássio e ácido amido sulfônico. Esses compostos químicos foram eficientes na remoção do $\mathrm{H}_{2} \mathrm{O}_{2}$, porém se constituíram em novos interferentes no teste de DQO. Por fim, os autores propuseram um modelo matemático de primeira ordem para eliminar o acréscimo no valor da DQO provocado pelo peróxido de hidrogênio (na faixa de 20 a $1000 \mathrm{mg} \mathrm{L}^{-1} \mathrm{O}_{2}$ ). Kang et $a l .{ }^{8}$ estudaram a correção do interferente peróxido de hidrogênio no teste padrão da DQO contendo como composto orgânico o biftalato de potássio (KHP). Os autores variaram a concentração do $\mathrm{H}_{2} \mathrm{O}_{2}$ de 0 a $2000 \mathrm{mg} \mathrm{L}^{-1}$ e do KHP em 85, 213 e $425 \mathrm{mg} \mathrm{L}^{-1}$. Para a correção da interferência provocada pelo agente redutor, concluiu-se que uma equação obtida por regressão dos pontos experimentais foi suficiente para as 3 amostragens do composto orgânico. Essa equação consistiu de um modelo de segunda ordem para o peróxido de hidrogênio e coeficiente de correlação de Pearson igual a 1. Kato et al. ${ }^{9}$ utilizaram-se da técnica de Redes Neurais Artificiais (RNA), por meio da arquitetura Backpropagation, para predizer a DQO de efluentes sintéticos (fenol, 
ácido salicílico, anilina e lignina) contendo interferentes inorgânicos (nitrato de sódio, nitrito de sódio, cloreto de sódio e sulfato de sódio), de efluentes sintéticos contendo caulim e de efluentes sintéticos contendo pigmento (Brilliant Blue). Todos os experimentos consistiram da etapa de treinamento da RNA e da etapa de validação contendo 10 amostras desconhecidas da fase de treinamento dos 4 grupos de efluentes. Na etapa de validação, os autores alcançaram erro médio de $9,8 \%$ para as amostras contendo mistura dos compostos orgânicos, de $12,67 \%$ para as amostras orgânicas contendo interferentes inorgânicos, de $19,94 \%$ para as amostras orgânicas contendo caulim e de 6,29\% para as amostras orgânicas contendo pigmentos.

O uso de correções de interferentes inorgânicos por simples regressão linear ou polinomial, ${ }^{7,8} \mathrm{em}$ determinações de DQO, constitui-se em um método inadequado e incorreto por desconsiderar possíveis interações entre as espécies presentes na matriz ambiental (efluente analisado) e as espécies interferentes. O método estatísticoexperimental, aqui apresentado, para correção dos interferentes analíticos íon ferroso e peróxido de hidrogênio apresenta-se como uma alternativa mais eficaz e coerente, uma vez que considera as possíveis interações matriz-interferentes, além de quantificar o peso de cada espécie sobre a DQO total. O uso de redes neurais artificiais, ${ }^{9}$ apesar de fornecer resultados favoráveis para correção de interferentes nas determinações de DQO, possui certas restrições, uma vez que não apresenta o mecanismo de iteração do processamento dos dados experimentais, visto que as redes neurais podem ser consideradas como uma "caixa de processamento", que pode ser treinada para que, a partir de um conjunto de entradas (input) forneça um conjunto de saída (output), porém, o conhecimento é armazenado numericamente em uma matriz de pesos neurais, sem explicitar a matemática envolvida no processo em estudo. Desta forma, a utilização de métodos estatísticos tradicionais, como planejamento de experimentos, ANOVA e teste t, se demonstra "transparente".

O objetivo deste trabalho foi utilizar a metodologia de Planejamento de Experimentos, em particular o Planejamento Fatorial, como ferramenta estatística na quantificação da interferência do íon ferroso e do peróxido de hidrogênio na determinação da DQO, uma vez que essas espécies químicas estão presentes em efluentes tratados por reagente de Fenton e por processos combinados $\mathrm{TiO}_{2}$ $+\mathrm{H}_{2} \mathrm{O}_{2}, \mathrm{O}_{3}+\mathrm{H}_{2} \mathrm{O}_{2}$ e $\mathrm{O}_{3}+\mathrm{Fe}^{2+}$. Também foi de interesse verificar o grau de confiança dado pelo modelo matemático empírico, gerado pela metodologia estatística, para validar o uso do mesmo, conjuntamente com dados experimentais obtidos ao acaso pertencentes ao domínio em estudo.

\section{PARTE EXPERIMENTAL}

Foram recolhidos $5 \mathrm{~L}$ de chorume do lixão de Guaratinguetá para a execução do estudo de interferência de $\mathrm{Fe}^{2+} \mathrm{e}_{2} \mathrm{O}_{2}$ sobre a variável-resposta DQO. Após a coleta, todo o volume de efluente foi acondicionado a $4{ }^{\circ} \mathrm{C} .{ }^{10} \mathrm{Um}$ segundo lote de chorume foi coletado para complementação do trabalho, estudando-se o efeito isolado das espécies inorgânicas na DQO do efluente. A diferença no tempo de coleta das duas amostragens foi de 1 ano.

As determinações de DQO foram realizadas de acordo com a metodologia padrão, ${ }^{2}$ que consiste em digestão em tubo fechado, seguida de determinação espectrofotométrica (espectrofotômetro Fentom 600) em $620 \mathrm{~nm}$. Utilizou-se chorume, com DQO real de $855 \pm 20 \mathrm{mg} \mathrm{L}^{-1}$, proveniente do lixão (32 anos de uso e desativado em 2006) da cidade de Guaratinguetá-SP (região do Vale do Paraíba), além de peróxido de hidrogênio e sulfato ferroso heptaidratado de grau analítico (marca Vetec). Em todos os experimentos do estudo de interferência do $\mathrm{Fe}^{2+}$ e do $\mathrm{H}_{2} \mathrm{O}_{2}$ sobre a resposta DQO, na matriz chorume, adicionou-se, primeiramente, solução de sulfato ferroso e, em seguida, solução de peróxido de hidrogênio sobre 50,0 mL de chorume in natura previamente homogeneizado. A mistura foi prontamente homogeneizada e adicionada (volume de 2,0 mL) nos tubos de DQO, procurando-se evitar a ação radicalar do reagente de Fenton na degradação da matéria orgânica presente no efluente. Em todos os experimentos, desde a adição do reagente de Fenton sobre o chorume até a introdução da amostra (chorume + reagente de Fenton) nos tubos de DQO, gastou-se o tempo máximo de $20 \mathrm{~s}$. Foram feitas quadruplicatas de todos os experimentos do estudo de interferência inorgânica na DQO.

Primeiramente, fez-se a validação estatística da curva de calibração de DQO por meio do cálculo de incerteza total expandida na preparação do padrão de biftalato de potássio (KHP), na preparação dos tubos de DQO e do estudo de repetibilidade/reprodutibilidade (RR). As determinações de DQO, feitas em quadruplicatas verdadeiras, foram realizadas seguindo um planejamento fatorial completo a 3 níveis, usando chorume e reagente de Fenton, resultando em um total de 36 experimentos. ${ }^{11}$ A Tabela 1 mostra os valores de concentração de $\mathrm{H}_{2} \mathrm{O}_{2}$ e de $\mathrm{Fe}^{2+}$ para cada nível estudado na matriz experimental, de acordo com Deng e Englehardt. ${ }^{3}$ Todas análises estatísticas foram feitas em ambiente Minitab Release $14^{\circledR}$.

Tabela 1. Concentrações de $\mathrm{Fe}^{2+}$ e de $\mathrm{H}_{2} \mathrm{O}_{2}$ correspondentes a cada nível da matriz experimental $3^{2}$

\begin{tabular}{lcc}
\hline Níveis & $\mathrm{Fe}^{2+}\left(\mathrm{mg} \mathrm{L}^{-1}\right)$ & $\mathrm{H}_{2} \mathrm{O}_{2}\left(\mathrm{mg} \mathrm{L}^{-1}\right)$ \\
\hline 1 & 99,45 & 199,06 \\
2 & 353,61 & 1279,69 \\
3 & 596,72 & 2488,29 \\
\hline
\end{tabular}

Após a obtenção do modelo matemático empírico (estudo de interferência de espécies inorgânicas na DQO) gerado com os dados do planejamento de experimentos, utilizou-se de um segundo lote de chorume in natura para avaliar a ação isolada dos íons ferroso e férrico, além do peróxido de hidrogênio, sobre a variável-resposta. Também foi feita análise de DQO em água deionizada com as espécies inorgânicas (em isolado) ferroso, férrico e peróxido de hidrogênio. A Tabela 2 mostra o conjunto de experimentos para avaliação, em isolado, das espécies inorgânicas ferroso, férrico e peróxido de hidrogênio em chorume in natura e em água deionizada.

\section{RESULTADOS E DISCUSSÃO}

\section{Obtenção da curva de calibração da DQO}

De acordo com a metodologia padrão,$^{2} \mathrm{o}$ padrão de biftalato de potássio (KHP) com concentração de $425 \mathrm{mg} \mathrm{L}^{-1}$ possui DQO teórica de $500 \mathrm{mg} \mathrm{L}^{-1}$. Verificou-se que a literatura pertinente ao cálculo teórico de DQO é escasso. ${ }^{12}$

Durante a reação de oxirredução entre a matéria orgânica e o dicromato de potássio, em meio ácido, há mudança de valência do oxigênio, de -2 a 0, conforme mostra a Equação 2. Assim, verifica-se que há transferência de um total de 4 mol de elétrons por $1 \mathrm{~mol}$ de $\mathrm{O}_{2}$ gerado. Por isso, o $\mathrm{O}_{2}$ gerado por oxirredução tem equivalente igual a 8 eq $\mathrm{g}$.

$$
\mathrm{O}^{2-} \stackrel{\mathrm{HgSO}_{4} / \mathrm{AgSO}_{4} / \mathrm{H}_{2} \mathrm{SO}_{4}}{\longrightarrow} \mathrm{O}_{2}
$$

A Equação 3 mostra o cálculo empregado para determinação teórica da massa de oxigênio gerada, utilizando a igualdade de equivalência entre os agentes oxidante e redutor. Fazendo uso de 2,0 mL de amostra, tem-se valor de DQO teórica máxima determinada igual a $2000 \mathrm{mg} \mathrm{L}^{-1} \mathrm{O}_{2}$, com utilização de $0,5 \mathrm{~mL}$ de $\mathrm{K}_{2} \mathrm{Cr}_{2} \mathrm{O}_{7}$ a 1 eq $\mathrm{L}^{-1}$. 
Tabela 2. Experimentos de determinação da ação isolada das espécies inorgânicas ferroso e peróxido de hidrogênio sobre a DQO na matriz chorume e das espécies ferroso, férrico e peróxido de hidrogênio sobre a DQO na matriz água deionizada

\begin{tabular}{lcccc}
\hline Experimento $\mathrm{n}^{\mathbf{0}}$ & Amostra & $\mathrm{Fe}^{2+}\left(\mathrm{mg} \mathrm{L}^{-1}\right)$ & $\mathrm{Fe}^{3+}\left(\mathrm{mg} \mathrm{L}^{-1}\right)$ & $\mathrm{H}_{2} \mathrm{O}_{2}\left(\mathrm{mg} \mathrm{L}^{-1}\right)$ \\
\hline 1 & Água & 597,49 & - & - \\
2 & Chorume & 597,49 & - & - \\
3 & Chorume & - & - & 2500,16 \\
4 & Água & - & - & 2500,16 \\
5 & Água & - & 595,47 & - \\
\hline
\end{tabular}

$\left(n_{e}\right)_{K_{2} C_{2} O_{7}}=\left(n_{e}\right)_{O_{2}} \therefore(N V)_{K_{2} C_{2} O_{7}}=\left(\frac{m}{E}\right)_{O_{2}} \therefore 1.0,0005=\frac{m}{8} \therefore m=0,004 g O_{2}(3)$

A Equação 4 mostra a reação química entre o KHP e o agente oxidante dicromato de potássio. ${ }^{1}$

$2 \mathrm{KC}_{8} \mathrm{H}_{5} \mathrm{O}_{4}+10 \mathrm{~K}_{2} \mathrm{Cr}_{2} \mathrm{O}_{7}+41 \mathrm{H}_{2} \mathrm{SO}_{4} \rightarrow 16 \mathrm{CO}_{2}+46 \mathrm{H}_{2} \mathrm{O}+10 \mathrm{Cr}_{2}\left(\mathrm{SO}_{4}\right)_{3}+11 \mathrm{~K}_{2} \mathrm{SO}_{4}$

Com base no cálculo estequiométrico referente à Equação 4 é possível verificar a quantidade de oxigênio requerida (DQO) para degradação completa do biftalato de potássio. Verifica-se que para cada 1 mol de $\mathrm{KC}_{8} \mathrm{H}_{5} \mathrm{O}_{4}$ degradado geram-se $8 \mathrm{~mol} \mathrm{de} \mathrm{CO}_{2}$, o que implicaria o consumo de $8 \mathrm{~mol} \mathrm{O}_{2}$ na degradação do padrão. Assim, para solução de KHP com concentração igual a 1722,28 mg L-1 obtém-se uma DQO igual a $2158,96 \mathrm{mg} \mathrm{L}^{-1}$ de $\mathrm{O}_{2}$. Fazendo as devidas diluições e respeitando o limite máximo de $2000 \mathrm{mg} \mathrm{L}^{-1}$ de $\mathrm{O}_{2}$ (Equação 3), foi construída a curva de calibração de DQO, conforme Figura 1.

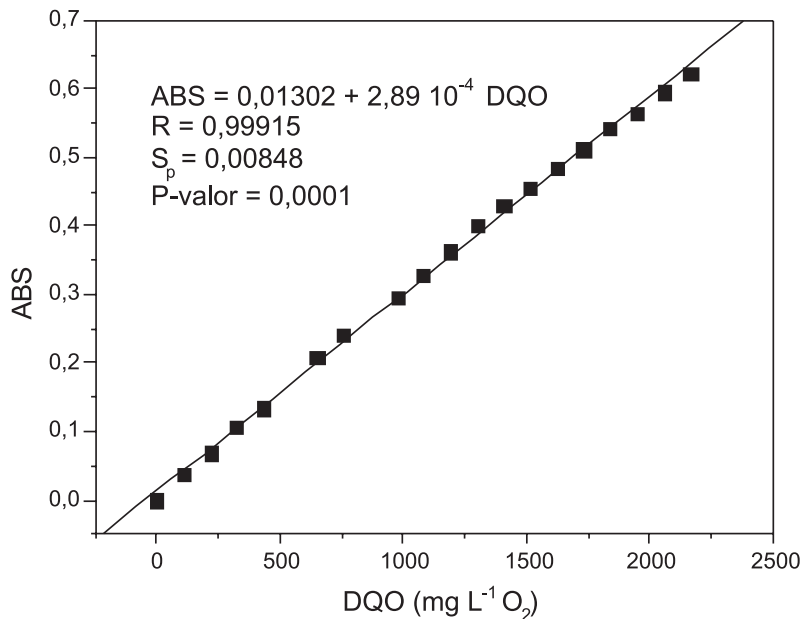

Figura 1. Curva de calibração para determinação espectrofotométrica da $D Q O$

Verifica-se que a curva de calibração obtida espectrofotometricamente (Figura 1) possui parâmetros que refletem boa qualidade dos resultados experimentais: coeficiente de correlação de Pearson próximo de $1(\mathrm{R}=0,99915)$, baixo valor do desvio-padrão $\left(\mathrm{S}_{\mathrm{p}}=\right.$ 0,00848 ) e grau de confiança igual a $99,99 \%$.

\section{Validação estatístico-experimental da curva de calibração da DQO}

Inicialmente, determinou-se a incerteza total expandida ${ }^{13}$ gerada na preparação da solução padrão de biftalato de potássio. Assim, foi feita a determinação da incerteza envolvida na pesagem, na solubilização e na pureza do padrão. A Tabela 3 mostra os valores das incertezas parciais para cada fonte específica. Conforme dados da Tabela 3, verifica-se que o erro total envolvido na preparação do padrão de KHP é baixo $\left(5,97 \mathrm{mg} \mathrm{L}^{-1}\right)$, correspondendo a apenas $0,35 \%$ do valor nominal da concentração. Portanto, a concentração de KHP utilizada na obtenção da curva de calibração da DQO é de $1722,28 \pm 5,97 \mathrm{mg} \mathrm{L}^{-1}$.

Tabela 3. Incertezas envolvidas na preparação da solução padrão de biftalato de potássio

\begin{tabular}{lc}
\hline Fonte de incerteza & Valor da incerteza \\
\hline Pesagem & $0,367 \mathrm{mg}$ \\
Solubilização do padrão & $0,788 \mathrm{~mL}$ \\
Pureza do padrão & 0,0006 \\
\hline
\end{tabular}

Também foi aplicado teste de repetibilidade/reprodutibilidade (RR) sobre os dados espectrofotométricos obtidos por 3 analistas e um grupo de 4 amostras. A Tabela 4 mostra os resultados do estudo $R R$.

Tabela 4. Estudo de repetibilidade/reprodutibilidade (RR) de um conjunto de 4 amostras utilizadas na obtenção da curva de calibração de DQO e 3 diferentes analistas

\begin{tabular}{lcc}
\hline Fonte de erro & Variância & Porcentagem de contribuição \\
\hline Total RR & 0,0009098 & 9,05 \\
Repetibilidade & 0,0005689 & 5,66 \\
Reprodutibilidade & 0,0003409 & 3,39 \\
Peça-a-peça & 0,0091442 & 90,95 \\
Total & 0,0100540 & 100,00 \\
\hline
\end{tabular}

Verifica-se na Tabela 4 que o erro total envolvendo os analistas e o equipamento de medição (espectrofotômetro) possui valor igual a $9,05 \%$ (menor que $10 \%$ ), ${ }^{14}$ indicando que o sistema de medição global é confiável. Também é possível constatar que o erro envolvendo o equipamento de medição (repetibilidade $=5,66 \%$ ) é maior que o erro envolvendo os analistas (reprodutibilidade $=3,39 \%$ ), o que reforça a confiabilidade dos dados apresentados pela curva de calibração da DQO. ${ }^{14}$ Tendo sido encontrado baixo valor da incerteza total expandida no preparo do padrão de KHP, e bons resultados no teste RR, tem-se confiabilidade nos resultados experimentais obtidos a partir da curva de calibração de DQO (estudo de interferência de espécies inorgânicas na DQO).

Por fim, no estudo de validação estatístico-experimental da curva de calibração da demanda química de oxigênio, foi feita a determinação do erro experimental envolvido na preparação dos tubos de DQO, conforme Tabela 5. No preparo dos tubos de DQO, utilizando como material volumétrico pipetas de vidro $(2,0 \mathrm{~mL})$ e automática com volume variável (100 a $1000 \mu \mathrm{L})$, têm-se como incerteza total o valor de 0,0043101 , na adição das soluções e amostra nos tubos de DQO. O valor da repetitividade do preparo dos tubos de Hach é de 
0,0002887. Assim, com os resultados das incertezas totais do KHP, do $\mathrm{K}_{2} \mathrm{Cr}_{2} \mathrm{O}_{7}$, da adição dos volumes e da repetitividade, obtém-se incerteza total de 0,049. Para valor nominal de DQO igual a 1000 $\mathrm{mg} \mathrm{L}{ }^{-1}$, tem-se incerteza combinada igual a $49 \mathrm{mg} \mathrm{L}^{-1}$ e incerteza expandida igual a $98 \mathrm{mg} \mathrm{L}^{-1}$, resultando em erro máximo de 9,8\% na resposta nominal. Conforme Zamora et al.,${ }^{15}$ determinações padrões (digestão em sistema fechado) de DQO apresentam desvios de até $30 \%$. Assim, o erro analítico-experimental da ordem de $10 \%$ está em acordo com informações da literatura.

Tabela 5. Incertezas envolvidas na preparação dos tubos de DQO da curva de calibração

\begin{tabular}{lcc}
\hline Fonte de erro & KHP & $\mathrm{K}_{2} \mathrm{Cr}_{2} \mathrm{O}_{7}$ \\
\hline Pesagem $(\mathrm{mg})$ & 0,1290994 & 12,909944 \\
Solubilização $(\mathrm{mL})$ & 0,2729812 & 0,674438 \\
Pureza (\%) & 0,00288675 & 0,0057735 \\
Massa Molar $\left(\mathrm{g} \mathrm{mol}^{-1}\right)$ & 0,00376530 & 0,001230176 \\
Incerteza total & 0,03855914 & 0,00587074 \\
\hline
\end{tabular}

\section{Estudo de interferência do $\mathrm{Fe}^{2+}$ e $\mathrm{H}_{2} \mathrm{O}_{2}$ sobre a DQO de chorume maduro}

A Tabela 6 mostra os resultados experimentais de DQO obtidos em cada experimento da matriz fatorial.

Tabela 6. Valores de DQO, $\mathrm{mg} \mathrm{L}^{-1}$, obtidos em cada experimento da matriz fatorial $3^{2}$

\begin{tabular}{cccccc}
\hline \multirow{2}{*}[\mathrm{Fe}^{2+}]{} & {$\left[\mathrm{H}_{2} \mathrm{O}_{2}\right]$} & \multicolumn{5}{c}{ Quadruplicatas da DQO $\left(\mathrm{mg} \mathrm{L}^{-1}\right)$} \\
& 1 & 925,16 & 984,07 & 928,62 & 987,53 \\
1 & 2 & 1413,76 & 1379,11 & 1420,69 & 1382,57 \\
1 & 3 & 1829,59 & 1846,92 & 1836,52 & 1791,47 \\
1 & 1 & 883,57 & 848,92 & 845,46 & 828,13 \\
2 & 2 & 1334,06 & 1254,36 & 1295,94 & 1295,94 \\
2 & 3 & 1836,52 & 1833,06 & 1843,45 & 1826,13 \\
2 & 1 & 904,37 & 713,78 & 835,06 & 835,06 \\
3 & 2 & 1299,41 & 1275,15 & 1264,75 & 1257,82 \\
3 & 3 & 1850,38 & 1826,13 & 1815,73 & 1919,69 \\
3 & & & & & \\
\hline
\end{tabular}

Com os resultados de DQO obtidos com a matriz fatorial $3^{2}$ foi possível obter um modelo matemático empírico de primeira ordem, conforme observado pela Equação 5. Verifica-se pela Equação 5 que o modelo empírico apresenta coeficiente negativo para o íon ferroso, o que, em primeiro momento, demonstra contrariar o efeito de interferência positiva do metal. ${ }^{2}$ Observa-se no modelo proposto que a contribuição negativa da concentração de íon ferroso pode ser considerada desprezível em função do termo de interação entre ferro solúvel e peróxido de hidrogênio, quanto maior for a concentração de peróxido de hidrogênio, conforme demonstrado pelos dados da Tabela 7. Nas condições 1, 2 e 3 de simulação, onde a concentração de ferro solúvel encontra-se no nível baixo, o $2^{\circ}$ termo é anulado pelo $4^{\circ}$ termo da Equação 5, uma vez que o somatório (valor absoluto) de ambos os termos é menor que o erro da curva de calibração da DQO (drift $=-44 \mathrm{mg} \mathrm{L}^{-1} \mathrm{O}_{2}$ ). Nas condições 3, 6 e 9 de simulação, nas quais se tem nível alto para $\mathrm{H}_{2} \mathrm{O}_{2}$, o somatório do $2^{\circ}$ e $4^{\circ}$ termos da Equação 5 representa valor praticamente nulo, sendo a contribuição de interferência dada pelo $3^{\circ}$ termo. Ainda deve ser considerado o grau de complexidade da matriz chorume, ${ }^{16} \mathrm{com}$ a possibilidade de reações paralelas entre os compostos que constituem o reagente de Fenton e os constituintes individuais e/ou combinados do efluente. Reações estas que podem interferir significativamente no resultado de DQO, positiva ou negativamente, potencializando ou não o efeito dos interferentes $\mathrm{Fe}^{2+} \mathrm{e}_{2} \mathrm{O}_{2}$.

$$
D Q O_{\text {TOTAL }}=912-0,347\left[\mathrm{Fe}^{2+}\right]+0,370\left[\mathrm{H}_{2} \mathrm{O}_{2}\right]+0,000144\left[\mathrm{Fe}^{2+}\right]\left[\mathrm{H}_{2} \mathrm{O}_{2}\right](5)
$$

Para validar o modelo matemático empírico e garantir a confiabilidade do mesmo, ${ }^{11}$ utilizaram-se 3 ferramentas estatísticas (análise gráfica dos resíduos, ANOVA e teste $t$ de significância) e de um conjunto adicional de dados experimentais intermediários ao domínio das variáveis de entrada do planejamento fatorial. A Figura 2 mostra o gráfico de probabilidade normal percentual contra os valores dos resíduos.

Conforme a Figura 2, verifica-se que 91,7\% dos pontos experimentais analisados (total de 36 ), provenientes da matriz fatorial $3^{2}$, possuem comportamento normal e os valores dos resíduos estão distribuídos simetricamente ao redor de zero, mostrando a confiabilidade dos pontos experimentais gerados. Mesmo havendo alguns pontos experimentais $(8,3 \%)$ fora da reta normal, não se deve excluí-los antes de uma análise mais apurada com a ANOVA. Segundo Montgomery, ${ }^{11}$ a análise de resíduos deve anteceder e ser uma parte automática da Análise de Variância no momento de garantir a viabilidade do modelo matemático. Com os dados da Tabela 6 obteve-se a Análise de Variância das variáveis de entrada e da interação entre elas, conforme Tabela 8. A Tabela 8 mostra os resultados referentes à ANOVA dos fatores concentração de íon ferroso $\left[\mathrm{Fe}^{2+}\right]$, concentração do peróxido de hidrogênio $\left[\mathrm{H}_{2} \mathrm{O}_{2}\right]$ e da interação entre ambos $\left[\mathrm{Fe}^{2+}\right]\left[\mathrm{H}_{2} \mathrm{O}_{2}\right]$. A Tabela 9 mostra o teste $t$ de significância dos coeficientes de predição associados ao modelo matemático empírico.

Tabela 7. Simulação dos termos $\left(2^{\circ} \mathrm{T}, 3^{\circ} \mathrm{T}\right.$ e $\left.4^{\circ} \mathrm{T}\right)$ de interferência do modelo matemático empírico, de acordo com os níveis baixo, médio e alto das concentrações de $\mathrm{Fe}^{2+}$ e $\mathrm{H}_{2} \mathrm{O}_{2}$ do planejamento de experimentos

\begin{tabular}{|c|c|c|c|c|c|c|c|}
\hline $\mathrm{N}$ & {$\left[\mathrm{Fe}^{2+}\right]\left(\mathrm{mg} \mathrm{L}^{-1}\right)$} & {$\left[\mathrm{H}_{2} \mathrm{O}_{2}\right]\left(\mathrm{mg} \mathrm{L}^{-1}\right)$} & $2^{\circ} \mathrm{T}$ & $3^{\circ} \mathrm{T}$ & $4^{\circ} \mathrm{T}$ & $2^{\circ} \mathrm{T}+4^{\mathrm{o}} \mathrm{T}$ & $\begin{array}{c}2^{\mathrm{o}} \mathrm{T}+3^{\mathrm{o}} \mathrm{T}+ \\
4^{\mathrm{o}} \mathrm{T}\end{array}$ \\
\hline 1 & 99,45 & 199,06 & $-34,51$ & 73,65 & 2,85 & $-31,66$ & 41,99 \\
\hline 2 & 99,45 & 1279,69 & $-34,51$ & 473,49 & 18,33 & $-16,18$ & 457,30 \\
\hline 3 & 99,45 & 2488,29 & $-34,51$ & 920,67 & 35,63 & 1,13 & 921,79 \\
\hline 4 & 353,61 & 199,06 & $-122,70$ & 73,65 & 10,14 & $-112,57$ & $-38,91$ \\
\hline 5 & 353,61 & 1279,69 & $-122,70$ & 473,49 & 65,16 & $-57,54$ & 415,94 \\
\hline 6 & 353,61 & 2488,29 & $-122,70$ & 920,67 & 126,70 & 4,00 & 924,67 \\
\hline 7 & 596,72 & 199,06 & $-207,06$ & 73,65 & 17,10 & $-189,96$ & $-116,31$ \\
\hline 8 & 596,72 & 1279,69 & $-207,06$ & 473,49 & 109,96 & $-97,10$ & 376,38 \\
\hline 9 & 596,72 & 2488,29 & $-207,06$ & 920,67 & 213,81 & 6,75 & 927,42 \\
\hline
\end{tabular}




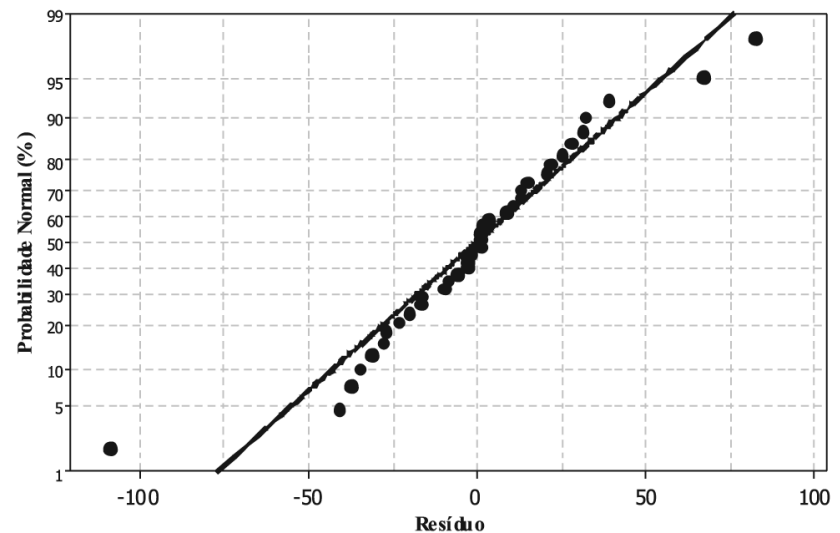

Figura 2. Probabilidade normal percentual contra resíduos obtidos entre os dados experimentais e os valores preditos pelo modelo matemático empírico

Como previsto, as variáveis independentes concentração de íon ferroso e concentração de peróxido de hidrogênio são significativas na análise de DQO com confiança de 99,99999\% apresentando altos valores no teste $F(15,02$ e 1976,44 , respectivamente - Tabela 8). Também verifica-se que há interação entre as variáveis de entrada com grau de confiança de 99,9\%. Essa resposta de interação é justificada por haver reação química entre ambas espécies. ${ }^{17}$

Pela Tabela 9 percebe-se que todos os coeficientes de predição são estatisticamente significativos com grau de confiança de $99,99999 \%$, sendo o coeficiente correspondente ao $\left[\mathrm{H}_{2} \mathrm{O}_{2}\right]$ o que apresenta maior significância (valor de $t 4,3$ vezes maior que o coeficiente do íon metálico). Assim, constata-se que o modelo apresentado (Equação 5) é representativo na predição de valores de DQO total para concentrações de $\mathrm{Fe}^{2+}$ e de $\mathrm{H}_{2} \mathrm{O}_{2}$, dentro da faixa estipulada. Esse modelo, no entanto, não pode ser utilizado para outras matrizes orgânicas, ficando restrito a essas espécies químicas. Também foi possível verificar que o modelo matemático é representativo para 99,1\% do conjunto de 36 resultados apresentados na Tabela 6.

Por fim, fez-se a validação do modelo matemático empírico por meio de dados experimentais não pertencentes ao conjunto gerador do modelo polinomial, porém pertencentes ao domínio estipulado das variáveis independentes. Os valores aleatórios das variáveis independentes, da DQO experimental e predita e o erro absoluto do modelo estão presentes na Tabela 10 .
Com os resultados da Tabela 10, para valores de concentração dos inorgânicos, verifica-se que há um baixo erro da DQO entre o valor esperado pelo modelo da Equação 5 e o resultado da DQO obtido por determinação espectrofotométrica, com variação do erro percentual absoluto de 0,29 a 10,98 , verificando que o modelo pode ser aplicado dentro do domínio estipulado inicialmente para as variáveis independentes. Contudo, conforme os experimentos 23, 24 e 25 , Tabela 10, a extrapolação da concentração de peróxido de hidrogênio em relação ao domínio estipulado pela matriz fatorial acarreta em erro absoluto superior a $20 \%$.

A Tabela 11 mostra os resultados experimentais obtidos na verificação do efeito isolado dos íons férrico e ferroso e do peróxido de hidrogênio na variável-resposta DQO, tanto para o segundo lote de chorume quanto para água deionizada. Nesta etapa, fez-se a determinação da demanda química de oxigênio para o chorume in natura homogeneizado, obtendo-se resposta de 1676,73 $\pm 30,00 \mathrm{mg}$ $\mathrm{L}^{-1}$. Percebe-se que esse resultado de DQO é 1,96 vezes maior que a DQO do primeiro lote de chorume utilizado no estudo apresentado.

Conforme dados dos experimentos 1 e 2, Tabela 11, verifica-se que o íon ferroso possui efeito negativo na variável-resposta DQO da ordem de $112 \mathrm{mg} \mathrm{L}^{-1} \mathrm{O}_{2}$ para concentração de 597, $49 \mathrm{mg} \mathrm{L}^{-1} \mathrm{Fe}^{2+}$. Essa resposta é condizente com os dados apresentados pela Tabela 6 e pela Equação 5 (coeficiente negativo do modelo matemático empírico). Pelo experimento 5 (Tabela 11), vê-se que o íon férrico, em água deionizada, possui efeito negativo da mesma ordem de grandeza $\left(132,37 \mathrm{mg} \mathrm{L}^{-1}\right)$ na resposta da DQO, tanto para o chorume quanto para a água deionizada. O efeito negativo de soluções aquosas dos íons ferroso e férrico pode ser justificado por possível inadequação da curva de calibração (Figura 1) para as espécies inorgânicas interferentes, podendo estar relacionado ao comprimento de onda $(620 \mathrm{~nm})$ utilizado nas determinações de absorbância. Pelos experimentos 3 e 4, verifica-se que o efeito do peróxido de hidrogênio na DQO é positivo, confirmando informações presentes na Tabela 6 e Equação 5. No entanto, utilizando concentração de peróxido de hidrogênio igual a $2500,16 \mathrm{mg} \mathrm{L}^{-1}$, constata-se que o seu efeito na variável-resposta é cerca de $1,7 \%$ vezes maior sobre a matriz água deionizada do que na matriz chorume ( $2^{\circ}$ lote).

A medida de DQO em função do tempo de amostras de chorume tratado pelos processos Fenton ou foto-Fenton é, pois, um resultado combinado da matéria orgânica residual (não oxidada durante a reação e ainda passível de oxidação pelo dicromato de potássio), do material inorgânico inerente à matriz e sujeito à oxidação pelo dicromato, de $\mathrm{Fe}^{2+}$ e de $\mathrm{H}_{2} \mathrm{O}_{2}$ residuais. Em situações de interesse, a aplicação do modelo proposto requer o conhecimento de $\left[\mathrm{Fe}^{2+}\right]$ e de $\left[\mathrm{H}_{2} \mathrm{O}_{2}\right]$ em função do

Tabela 8. ANOVA das variáveis independentes concentração de íon ferroso $\left[\mathrm{Fe}^{2+}\right]$ e concentração de peróxido de hidrogênio $\left[\mathrm{H}_{2} \mathrm{O}_{2}\right]$, e da interação entre os respectivos fatores $\left[\mathrm{Fe}^{2+}\right]\left[\mathrm{H}_{2} \mathrm{O}_{2}\right]$

\begin{tabular}{lccccc}
\hline Fonte & Graus de liberdade & Soma dos Quadrados & Soma Média dos Quadrados & $\mathrm{F}$ & $\mathrm{p}$ \\
\hline$\left[\mathrm{Fe}^{2+}\right]$ & 2 & 42212 & 21106 & 15,02 & 0,000 \\
{$\left[\mathrm{H}_{2} \mathrm{O}_{2}\right]$} & 2 & 5554372 & 2777186 & 1976,44 & 0,000 \\
{$\left[\mathrm{Fe}^{2+}\right]\left[\mathrm{H}_{2} \mathrm{O}_{2}\right]$} & 4 & 34875 & 8719 & 6,20 & 0,001 \\
Erro & 27 & 37939 & 1405 & \\
Total & 35 & 5669398 & & \\
\hline
\end{tabular}

Tabela 9. Teste t de significância dos coeficientes de predição do modelo empírico

\begin{tabular}{lcccc}
\hline Variável preditora & Coeficiente & Desvio padrão do coeficiente & $t$ & P \\
\hline Constante & 911,78 & 23,24 & 39,24 & 0,000 \\
{$\left[\mathrm{Fe}^{2+}\right]$} & $-0,34704$ & 0,05744 & $-6,04$ & 0,000 \\
{$\left[\mathrm{H}_{2} \mathrm{O}_{2}\right]$} & 0,36962 & 0,01435 & 25,76 & 0,000 \\
{$\left[\mathrm{Fe}^{2+}\right]\left[\mathrm{H}_{2} \mathrm{O}_{2}\right]$} & 0,00014414 & 0,00003547 & 4,06 & 0,000 \\
\hline
\end{tabular}


Tabela 10. Validação experimental do modelo matemático empírico por meio da aleatorização das concentrações de $\mathrm{Fe}^{2+}$ e $\mathrm{H}_{2} \mathrm{O}_{2}$

\begin{tabular}{|c|c|c|c|c|c|}
\hline Número do experimento & {$\left[\mathrm{Fe}^{2+}\right]$} & {$\left[\mathrm{H}_{2} \mathrm{O}_{2}\right]$} & DQO* teórica & $\mathrm{DQO}^{+}$experimental & Erro Absoluto (\%) \\
\hline 1 & 128,43 & 426,56 & 1033,15 & 1140,00 & 9,37 \\
\hline 2 & 128,43 & 710,94 & 1143,63 & 1146,93 & 0,29 \\
\hline 3 & 128,43 & 1066,41 & 1281,73 & 1340,99 & 4,42 \\
\hline 4 & 128,43 & 2132,82 & 1696,02 & 1826,13 & 7,12 \\
\hline 5 & 171,25 & 1066,41 & 1273,45 & 1237,03 & 2,94 \\
\hline 6 & 171,25 & 1777,35 & 1554,03 & 1576,63 & 1,43 \\
\hline 7 & 214,06 & 426,56 & 1008,70 & 1018,72 & 0,98 \\
\hline 8 & 214,06 & 710,94 & 1122,68 & 1077,63 & 4,18 \\
\hline 9 & 214,06 & 1066,41 & 1265,17 & 1254,36 & 0,86 \\
\hline 10 & 214,06 & 2132,82 & 1692,61 & 1794,94 & 5,70 \\
\hline 11 & 278,27 & 355,47 & 961,21 & 921,69 & 4,29 \\
\hline 12 & 278,27 & 1066,41 & 1252,74 & 1261,29 & 0,68 \\
\hline 13 & 278,27 & 2843,76 & 1981,58 & 2079,09 & 4,69 \\
\hline 14 & 428,11 & 710,94 & 1070,32 & 980,60 & 9,15 \\
\hline 15 & 428,11 & 1066,41 & 1223,76 & 1278,61 & 4,29 \\
\hline 16 & 428,11 & 2132,82 & 1684,07 & 1746,43 & 3,57 \\
\hline 17 & 535,14 & 355,47 & 885,22 & 925,16 & 4,32 \\
\hline 18 & 535,14 & 426,56 & 917,01 & 1004,86 & 8,74 \\
\hline 19 & 535,14 & 710,94 & 1044,14 & 1167,73 & 10,58 \\
\hline 20 & 535,14 & 1066,41 & 1203,06 & 1351,39 & 10,98 \\
\hline 21 & 535,14 & 1777,35 & 1520,89 & 1555,84 & 2,25 \\
\hline 22 & 535,14 & 2132,82 & 1679,81 & 1722,17 & 2,46 \\
\hline 23 & 128,43 & 4265,64 & 2524,61 & 2096,42 & 20,43 \\
\hline 24 & 214,06 & 4265,64 & 2547,49 & 2068,70 & 23,14 \\
\hline 25 & 428,11 & 4265,64 & 2604,70 & 2113,74 & 23,23 \\
\hline
\end{tabular}

${ }^{*}$ Resultados gerados por meio do modelo matemático empírico. ${ }^{+}$Resultados obtidos espectrofotomericamente

Tabela 11. Resultados dos experimentos de determinação da ação isolada das espécies inorgânicas ferroso e peróxido de hidrogênio sobre a DQO na matriz chorume e das espécies ferroso, férrico e peróxido de hidrogênio sobre a DQO na matriz água deionizada

\begin{tabular}{lccc}
\hline Experimento ${ }^{\circ}$ & Amostra & DQO & $\mathrm{Sp}$ \\
\hline 1 & Água & $-111,99$ & 1,17 \\
2 & Chorume & 1578,78 & 56,95 \\
3 & Chorume & 2688,83 & 83,13 \\
4 & Água & 1737,21 & 42,83 \\
5 & Água & $-132,37$ & 7,07 \\
\hline
\end{tabular}

tempo e sua previsão corresponde ao resultado de todas as contribuições elencadas anteriormente. Em última análise, o que se busca em determinações de DQO é unicamente a fração orgânica (DQO real). Assim, a DQO real pode ser estimada conhecendo-se as concentrações de $\mathrm{Fe}^{2+}$ e de $\mathrm{H}_{2} \mathrm{O}_{2}$ residuais e o grau de interferência proporcionado por ambos interferentes, por meio do modelo matemático empírico. Maior confiabilidade é conferida sobre a estimativa da DQO real, fazendo-se uma ampla caracterização do efluente, identificando-se possíveis interferentes inorgânicos de DQO como nitritos e sulfetos, por exemplo.

\section{CONCLUSÕES}

A metodologia de experimentos fatorial completo $3^{2}$ na determinação de demanda química de oxigênio em chorume maduro dopado com reagente de Fenton mostrou-se eficiente nesse tipo de estudo. Validou-se o modelo matemático empírico gerado pela matriz experimental por meio da Análise de Variância (ANOVA) e de ex- perimentos adicionais pertencentes ao domínio do conjunto gerador do modelo polinomial, variando-se as concentrações de peróxido de hidrogênio e do íon ferroso. Com a ANOVA foi possível obter um grau de confiança de 99,99999\% para o modelo matemático, e com os dados experimentais de validação obteve-se um erro médio de $4,70 \%$ e erro máximo de $9,37 \%$ da DQO predita em relação à DQO obtida espectrofotometricamente. Contudo, verificou-se que o modelo matemático empírico é válido unicamente para a amostra em estudo, dentro dos limites de concentração dos interferentes inorgânicos adotados na Análise Multivariada. Com a extrapolação da concentração do peróxido de hidrogênio, obteve-se erro absoluto superior a $20 \%$ durante a etapa de validação experimental do modelo empírico. Por fim, com um conjunto de dados dos interferentes $\mathrm{Fe}^{2+}$ e $\mathrm{H}_{2} \mathrm{O}_{2}$, em isolado, comprovou-se a ação negativa do ferro solúvel sobre a DQO do chorume e verificou-se que o efeito de interferência do peróxido de hidrogênio, a $2500 \mathrm{mg} \mathrm{L}^{-1}$, é 1,7 vezes maior sobre água que sobre o chorume.

\section{AGRADECIMENTOS}

À Coordenação de Aperfeiçoamento de Pessoal de Nível Superior (CAPES) pela bolsa de mestrado Demanda Social.

\section{REFERÊNCIAS}

1. Vaidya, B.; Watson, S. W.; Coldiron, S. J.; Porter, M. D.; Anal. Chim. Acta 1997, 357, 167.

2. APHA; Standard Methods for the Examination of Water and Wastewater, $19^{\text {th }}$ ed., Amer. Publ. Ass: Washington, 1999. 
3. Benatti, C. T.; Tavares, C. R. G.; Guedes, T. A.; J. Environ. Management 2006, 80, 66; Micaroni, R. C. C. M.; Bueno, M. I. M. S.; Jardim, W. F.; J. Braz. Chem. Soc. 2004, 15, 509; Tiburtius, E. R. L.; Zamora, P. P.; Emmel, A.; Leal, E. S.; Quim. Nova 2005, 28, 61; Tizaoui, C.; Bouselmi, L.; Mansouri, L.; Ghrabi, A.; J. Hazard. Mater. 2007, 140, 316; Deng, Y.; Englehardt, J. D.; Water Res. 2006, 40, 3683.

4. http://www.asq.org/learn-about-quality/data-collection-analysis-tools/ overview/ design-..., acessada em Fevereiro 2008.

5. Bonduelle, G. M.; Cerne 2000, 6, 1; Bortoleti, J. A.; Bruns, R. E.; Quim. Nova 2007, 30, 436.

6. Galdámez, E. V. C.; Dissertação de Mestrado, Universidade de São Paulo, Brasil, 2002.

7. Talinli, I.; Anderson, G. K.; Water Res. 1992, 26, 107.

8. Kang, Y. W.; Cho, M.; Hwang, K.; Water Res. 1999, 33, 1247.

9. Kato, Y.; Kumagai, T.; Nishioka, H.; Sugie, Y.; Orient. J. Chem. 2001, $17,1$.

10. Bila, D. M.; Montalvão, A. F.; Silva, A. C.; Dezotti, M.; J. Hazard. Mater. 2005, B117, 235; Zhang, H.; Choi, H. J.; Huang, C.; J. Hazard. Mater. 2005, B125, 166; Morais, J. L.; Zamora, P. P.; J. Hazard. Mater. 2005, B123, 181.

11. Montgomery, D. C.; Design and Analysis of Experiments, $5^{\text {th }}$ ed., Wiley: New York, 2001.

12. Zhang, Z.; Yuan, Y.; Fang, Y.; Liang, L.; Ding, H. ; Jin, L. ; Talanta 2007, 73, 523; Yu, H.; Wang, H.; Quan, X.; Chen, S.; Zhang, Y.; Electrochem. Commun. 2007, 9, 2280; Li, J.; Li, L.; Zheng, L.; Xian, Y.; Ai, S.; Jin, L.; Anal. Chim. Acta 2005, 548, 199; Li, J.; Li, L.; Zheng, L.; Xian, Y.; Jin, L.; Talanta 2006, 68, 765; Zhang, S.; Zhao, H.; Jiang, D.; John, R.; Anal. Chim. Acta 2004, 514, 89; Hu, Y.; Yang, Z.; Talanta 2004, 63, 521; Ai, S.; Li, J.; Yang, Y.; Gao, M.; Pan, Z.; Jin, L.; Anal. Chim. Acta 2004, 509, 237; Westbroek, P.; Temmerman, E.; Anal. Chim. Acta 2001, 437, 95; Lee, K.; Ishikawa, T.; McNiven, S. J.; Nomura, Y.; Hiratsuka, A.; Sasaki, S.; Arikawa, Y.; Karube, I.; Anal. Chim. Acta 1999, 398, 161; Lee, K.; Ishikawab, T.; McNivena, S.; Nomura, Y.; Sasakia, S.; Arikawab, Y.;
Karubea, I.; Anal. Chim. Acta 1999, 386, 211; Canelli, E.; Mitchell, D. G.; Pause, R. W.; Water Res. 1976, 10, 351; Hey, A. E.; Green, A.; Harkness, N.; Water Res. 1969, 3, 873; Sousa, A. C.; Lucio, M. M. L. M.; Bezerra Neto, O. F; Marcone, G. P. S.; Pereira, A. F. C.; Dantas, E. O.; Fragoso, W. D.; Araújo, M. C. U.; Galvão, R. K. H.; Anal. Chim. Acta 2007, 588, 231; Canals, A.; Cuesta, A.; Gras, L.; Hernández, M. R.; Ultrason. Sonochem. 2002, 9, 143; Hu, Z.; Chandran, K.; Smets, B. F.; Grasso, D.; Water Res. 2002, 36, 617; Mohan, S. V.; Mohan, S. K.; Reddy, S. J.; Water Res. 2000, 34, 3761; LaPara, T. M.; Alleman, J. E.; Pope, P. G.; Waste Management 2000, 20, 295; Lee, K; Ishikawa, T.; McNiven, S. J.; Nomura, Y.; Hiratsuka, A.; Sasaki, S.; Arikawa, Y.; Karube, I.; Anal. Chim. Acta 1999, 398, 161; Brocca, D.; Barilli, L.; Collina, E.; Lasagni, M.; Tettamanti, M.; Pitea, D.; Chemosphere 1997, 35, 2203; Bullock, C.M.; Bicho, P. A.; Zhang, Y.; Saddler, J. N.; Water Res. 1996, 30, 1280; Korenaga, T.; Zhou, X.; Okada, K.; Moriwake, T.; Anal. Chim. Acta 1993, 272, 237; Tian, L.; Wu, S.; Anal. Chim. Acta 1992, 261, 301; Appleton, J. M. H.; Tyson, J. F.; Mounce, R. P.; Anal. Chim. Acta 1986, 179, 269; Korenaga, T.; Ikatsu, H.; Anal. Chim. Acta 1982, 141, 301; Canelli, E.; Mitchell, D. G.; Pause, R. W.; Water Res. 1976, 10, 351; Hey, A. E.; Green, A.; Harkness, N.; Water Res. 1969, 3, 873.

13. Sena, M. M.; Collins, C. H.; Collins, K. E.; Scarminio, I. S.; Quim. Nova 2001, 24, 331; Chui, Q. S. H.; Zucchini, R. R.; Lichtig, J. ; Qualidade de medidas em Química Analítica. Estudo de caso:determinação de cádmio por espectrofotometria de Absorção Atômica; Comitê EUROCHEM/ RELACRE Em Exemplos de cálculos de incertezas, 2002.

14. ANFAVEA; Análise dos sistemas de medição, $1^{\mathrm{a}}$ ed., IQA, 1997.

15. Zamora, P. P.; Cordeiro, G. A.; Nagata, N.; Quim. Nova 2005, 28, 838.

16. Pacheco, J. R.; Zamora, P. G. P.; Eng. San. Amb. 2004, 4, 306; Wiszniowski, J.; Robert, D.; Surmacz-Gorska, J.; Miksch, K.; Malato, S.; Weber, J.; Appl. Catal., B 2004, 53, 127; Seo, D.; Kim, Y.; Ham, S.; Lee, D.; J. Hazard. Mater. 2007, 148, 679.

17. Vogel, A. I.; Química Analítica Cualitativa, $3^{\text {a }}$ ed., Kapelusz: Buenos Aires, 1969, p. 187. 